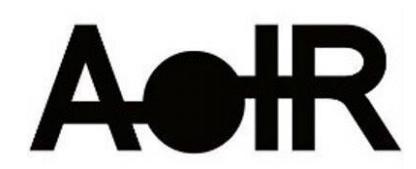

Selected Papers of \#AoIR2021:

The 22nd Annual Conference of the

Association of Internet Researchers

Virtual Event / 13-16 Oct 2021

\title{
NEGOTIATING PROFESSIONAL BELONGINGS: FINNISH ACTORS' AFFECTIVE ENGAGEMENTS ON SOCIAL MEDIA PLATFORMS
}

\author{
Anne Soronen \\ Tampere University \\ Anu Koivunen \\ University of Turku
}

In this paper, we examine how social media practices shape freelance actors' and theatre employees' professional lives, social relationships, and occupational selfconceptions. Social media platforms have changed the conditions of the production, distribution, and reception of creative works (Hadley, 2017; Nieborg \& Poell, 2018). Previous studies have shown that for creative professionals in precarious conditions, social media entail promotional work (e.g. Gandini et al., 2017). Many creative workers have transformed themselves into "promotional labourers" (Bollmer, 2018), regularly producing work-related social media content to increase their visibility and enhance their job opportunities.

Our study focuses on actors and their perceptions of social media as an area of professional agency. We ask how social media practices inform and shape actors' occupational self-conceptions and professional belongings. To answer this question, we employ Baym's (2018) concept of relational labour, which accounts for the endeavours of online communication musicians to build social relationships with audiences and ensure continued work. We read Baym's notion of relational labour through Berlant's (1988) conceptualisation of intimacy as mobile attachments to explore the consequences of platformed socialities for actors' professional selves.

We collected data from 15 Finnish professional actors from June 2020 to March 2021. The participants were eight freelancers and seven theatre employees, of whom nine were women and six were men, all white. Their ages ranged from 29 to 64 years. We applied the diary-interview method (e.g. Spowart \& Nairn, 2014) in an ethnographic framework. The participants kept free-form "digital everyday life" diaries for one week, after which they were interviewed using individually designed interview frames based on their diaries. Our analysis was based on a close reading of the interview material and

Soronen, A., \& Koivunen, A. (2021, October). Negotiating professional belongings: Finnish actors' affective engagements on social media platforms. Paper presented at AolR 2021: The 22nd Annual Conference of the Association of Internet Researchers. Virtual Event: AolR. Retrieved from http://spir.aoir.org. 
diary entries in which participants described their experiences and feelings concerning their presence, professional agency, and promotion on social media.

Our main finding is that while engaging in promotional work and attracting audiences on social media, Finnish actors foreground professional belonging rather than strategic self-branding. Our data confirm that creative workers prefer mutual support on social media - liking, emoting, and reposting - and perceive it as a means of securing collaborations (see Patel, 2017). Although manifesting belonging to professional communities is especially pertinent to freelancers, our findings suggest that colleagues, rather than the general audience, are the primary intended audience on Instagram and Facebook. This creates regular negotiations with collapsed contexts (Marwick \& Boyd, 2011) and imagined peer audiences for social media updates.

The actors in our study do not, as a rule, strategically seek new followers, and their approach to visibility is often complex or hesitant. The insecurity about when, how, and to whom one is visible occupies many participants' thoughts. Theatre employees commonly distance themselves from their organizations' official social media marketing. Also, some freelance actors often choose to ignore production companies' guidelines for social media promotion. Other freelancers describe checking promotional instructions carefully as a matter of routine. Some consider the operations of algorithms in trying to control their visibility.

Second, all participants reflect on the increasingly important role of social media presence in employability, although estimations of its importance vary. Actors make considerable efforts to foster a sense of belonging to the professional community. Some worry about the reputational disadvantage of social media presence, seeing digital traces and social media archives as potential threats to future employability, whereas others find them beneficial for new job opportunities. For participants active on Instagram, the ephemerality associated with the Story feature has reduced the sense of platform dependency.

Third, our data support the findings of Leidner (2016), who, studying how actors manage labour force oversupply and precarity, documented a durable commitment to occupational identity. However, among Finnish actors, the primacy of professional identity also results in ambivalence and contradictory feelings about social media posting (e.g. Lehto, 2021). Whereas one participant describes elaborate tactics of using props as a way of managing the genre of selfies, another participant depicts updating and sharing selfies on social media as a gradual process of unlearning shame by getting used to it and managing ambivalent affects. Some prefer to share behind-thescenes material, whereas others wish to maintain secrecy about their characters and production processes (cf. Turner, 2017). Negotiating the different notions of openness and authenticity between artistic professions and social media, the participants reflect on the productions in which they are involved and the roles that they play, seeking a balance in sharing content proportional to the size of their respective roles and productions.

The participants negotiate their online actions related to imagined peer assessments in a way that involves continuous movements between visibility and invisibility and 
between independence and interdependence. Anxieties, ambivalences, and uncertainties about one's social media presence are entangled with the actors' professional self-conceptions. While manifestations of mutual support are perceived as performances of professional networks and friendships before a general audience, they are simultaneously viewed as important acts of community building, signalling belonging and expressing aspirations among peers.

To conclude, we suggest that relational labour on social media needs to be studied as a phenomenon of complex belongings to account for professional community building rather than mere strategic self-promotion. More research is needed on the subtle boundaries and overlapping intimacies between peers and the general audience to gain deeper insights into the complexities and mobile attachments that define the lived experiences of these platforms.

\section{References}

Baym, N. (2018). Playing to the crowd: Musicians, audiences, and the intimate work of connection. New York University Press.

Berlant, L. (1998). Intimacy: A special issue. Critical Inquiry, 24(2), 281-288. https://doi.org/10.1086/448875

Bollmer, G. (2018). Software intimacies (social media and the unbearability of death). In A. Dobson, B. Robards, \& N. Carah (Eds.), Digital intimate publics and social media (pp. 45-58). Palgrave Macmillan.

Gandini, A., Bandinelli, C., \& Cossu, A. (2017). Collaborating, competing, co-working, coalescing: Artists, freelancers and social entrepreneurs as the 'new subjects' of the creative economy. In J. Graham \& A. Gandini (Eds.), Collaborative production in the creative industries (pp. 15-32). University of Westminster Press.

Hadley, B. (2017). Theatre, social media, and meaning making. Springer International Publishing AG.

Leidner, R. (2016). Work identity without steady work: Lessons from stage actors. In S. Vallas (Ed.), Research in the sociology of work: Vol 3. Research in the sociology of work (pp. 3-35). Emerald.

Lehto, M. (2021). Ambivalent influencers: Feeling rules and the affective practice of anxiety in social media influencer work. European Journal of Cultural Studies. https://doi.org/10.1177/1367549421988958

Marwick, A., \& Boyd, D. (2011). I tweet honestly, I tweet passionately: Twitter users, context collapse, and the imagined audience. New Media \& Society, 13(1), 114-133. https://doi.org/10.1177/1461444810365313 
Nieborg, D. B., \& Poell, T. (2018). The platformization of cultural production: Theorizing the contingent cultural commodity. New Media \& Society, 20(11), 4275-4292.

https://doi.org/10.1177/1461444818769694

Patel, K. (2017). Expertise and collaboration: Cultural workers' performance on social media. In J. Graham \& A. Gandini (Eds.), Collaborative production in the creative industries (pp.157-176). University of Westminster Press.

Spowart, L., \& Nairn, K. (2014). (Re)performing emotions in diary-interviews. Qualitative Research, 14(3), 327-340. https://doi.org/10.1177/1468794112473498

Turner, P. (2019). Fast marketing, furious interactions: An interstellar community on Instagram. Celebrity Studies, 10(4), 469-478.

https://doi.org/10.1080/19392397.2019.1672997 